\title{
COMPORTAMENTO ALIMENTAR DE RATOS ADULTOS SUBMETIDOS À RESTRIÇÃO PROTÉICA CUJAS MÃES SOFRERAM DESNUTRIÇÃO DURANTE A LACTAÇÃO
}

\section{FEEDING BEHAVIOR OF ADULT RATS SUBMITTED TO PROTEIN MALNUTRITION WHOSE MOTHERS RECEIVED PROTEIN RESTRICTED DIETS DURING LACTATION}

\author{
Magna Cottini da Fonseca PASSOS' \\ Cristiane da Fonte RAMOS ${ }^{2}$ \\ Cíntia Vilanova TEIXEIRA ${ }^{3}$ \\ Egberto Gaspar de MOURA ${ }^{3}$
}

RESUMO

\begin{abstract}
Foi avaliado o consumo alimentar de animais adultos submetidos à restrição protéica, cujas mães receberam dieta hipoprotéica ou hipocalórica na lactação: controle (C) ração normal com 23\% de proteína; restrição protéica (RP) 8\% de proteína; restrição energética (RE) 23\% de proteína, em quantidade restrita à ingerida pelo grupo restrição protéica. Após o desmame todos os filhotes receberam ração normal até 60 dias e nesta época foram submetidos, por 21 dias, ao seguinte tratamento: (C/C)-filhotes de mães $C$ recebendo ração normal; (restrição protéical controle)-filhotes de mães Controle, recebendo ração hipoprotéica; (C/RP)-filhotes de mães $R P$ recebendo ração normal; $(R P / R P)$-filhotes de mães $R P$ recebendo ração hipoprotéica; (C/RE)-filhotes de mães $R E$ recebendo ração normal; ( $R P / R E$ )-filhotes de mães $R E$ recebendo ração hipoprotéica. Os filhotes de mães RP consumiram menos ração até 57 dias $(p<0,01)$, enquanto os filhotes de mães RE normalizaram a ingestão aos 37 dias. Aos 81 dias, os animais submetidos à restrição protéica consumiram menos ração $(p<0,01)$. A dieta materna na lactação modificou o consumo alimentar e o peso corporal da prole na vida adulta, estando, possivelmente, a restrição protéica associada a uma alteração permanente no controle hipotalâmico da seleção de nutrientes da prole.
\end{abstract}

Termos de indexação: lactação, restrição protéica, conduta na alimentação, desnutrição protéica.

\section{ABSTRACT}

This study evaluated food intake of adult animals whose mothers received protein- or energy-restricted diets during lactation as follows: control (C)- $23 \%$ of protein; protein-restricted (PR)

(1) Departamento de Nutrição Aplicada, Instituto de Nutrição, Universidade do Estado do Rio de Janeiro. Rua São Francisco Xavier, 524, 12ªndar, 20559-900, Rio de Janeiro, RJ, Brasil. Correspondência para/Correspondence to: M.C.F.PASSOS.E-mail: magna@uerj.br

(2) Departamento de Anatomia, Instituto de Biologia, Universidade do Estado do Rio de Janeiro.

(3) Departamento de Ciências Fisiológicas, Instituto de Biologia, Universidade do Estado do Rio de Janeiro. 


\begin{abstract}
- $8 \%$ of protein; energy-restricted (ER) - 23\% of protein, restricted in quantity. After weaning all pups received the control diet until 60 days, when they were separated into groups, with free access to the following diets during 21 days: (C/C)- pups of control dams fed control diet; (PR/C)-pups of control dams fed protein-restricted diet; (C/PR)- pups of protein-restricted dams fed control diet; (PR/PR)-pups of protein-restricted dams fed protein-restricted diet; (C/ER)-pups of energy-restricted dams fed control diet; (PR/ER)-pups of energy-restricted dams fed protein-restricted diet. Pups of protein-restricted dams consumed less food until day $57(p<0.01)$, while pups of energy-restricted dams normalized their ingestion at 37 days. At 81 days, all malnourished animals consumed less food than the control $(p<0.01)$. The kind of diet consumed in the lactation period changed the food intake and the body weight of the offspring in the adulthood. So, the protein restriction can possibly be associated with a permanent alteration in the hypothalamic control of nutrients selection of the offspring.
\end{abstract}

Index terms: lactation, protein restriction, feeding behavior, protein malnutrition.

\section{INTRODUÇÃO}

A desnutrição tem sido reconhecida, através dos séculos, como um problema mundial. Estima-se que no mundo mais de um terço das crianças menores de 5 anos sofram de desnutrição grave ou moderada, sendo que $80 \%$ são asiáticas, $15 \%$ africanas e $5 \%$ latino-americanas. Um total de $43 \%$ das crianças em países em desenvolvimento sofreram desnutrição em algum momento de suas vidas (Onís et al., 1993).

Em função da alta prevalência de desnutrição nos países em desenvolvimento é importante a realização de trabalhos experimentais a fim de avaliar suas conseqüências nos diversos sistemas orgânicos.

Estudos, em nosso laboratório, avaliando o efeito da restrição protéica durante a lactação sobre a função tireóidea das mães, demonstraram que reduções severas na relação proteína/energia na dieta destes animais promovem um distúrbio no comportamento alimentar, diminuindo em aproximadamente $50 \%$ o consumo diário de ração (Ramos et al., 2000). Rostom de Melo et al. (1989) e Pine et al. (1994) demonstraram alteração semelhante no comportamento alimentar de ratas lactantes. No entanto, Wurtman (1983) observou que ratos adultos, alimentados com ração isoenergética e diferentes quantidades de proteínas e glicídios, ajustavam o consumo de maneira que os aportes protéicos representavam uma proporção constante dos aportes energéticos consumidos. Assim, esta alteração no comportamento alimentar parece não ser específica da fase de lactação.

As causas das alterações no comportamento alimentar destes animais ainda não foram completamente elucidadas. Sabe-se há muito tempo que o hipotálamo está implicado na regulação dos aportes energéticos e, é provável que a seleção dos nutrientes também influencie a atividade das regiões hipotalâmicas (Wurtman,1983; Anderson et al., 1984). A modificação da concentração de substratos energéticos no plasma, induzida pela alimentação, influencia a síntese de certos neurotransmissores no sistema nervoso central. A serotonina é o neurotransmissor que tem a função melhor documentada; além de sua ação sobre a saciedade parece ter uma função no equilíbrio glicídico-protéico da alimentação (Basdevant et al., 1995).

Alguns pesquisadores mostraram que a restrição protéica em ratas lactantes pode levar a alterações metabólicas e fisiológicas na prole que podem ser permanentes, mesmo que o animal tenha livre acesso à ração normal após o desmame (Moura et al., 1996; Ramos et al., 1997; Passos et al., 2000). Estes estudos reforçam o conceito de "imprinting metabólico" (Waterland \& Garza, 1999) que se traduz por uma alteração permanente de uma determinada função, conseqüente à algum evento ocorrido em um período crítico nos primeiros dias de vida.

Não existem relatos na literatura da associação entre restrição protéica na vida adulta e condições nutricionais das mães durante a lactação. Assim, desenvolvemos um modelo experimental para avaliar a resposta à desnutrição protéica, em relação ao comportamento alimentar, em animais cujas mães sofreram desnutrição protéica ou energética durante a lactação.

\section{MATERIAL E MÉTODOS}

Ratas Wistar foram mantidas em biotério com temperatura controlada $\left(25 \pm 1^{\circ} \mathrm{C}\right)$ e ciclo artificial de claro-escuro (luz de 7 às 19h). Aos três meses de idade foram acasaladas e após o acasalamento foram mantidas em gaiola individual com livre acesso à água e ração até o dia do nascimento da ninhada. Foram seguidos os princípios básicos de manuseio e cuidado com os animais descritos em Guide for the Care and Use of Laboratory Animals (Bayne, 1996).

Após o nascimento da ninhada as ratas foram divididas nos seguintes grupos: (C) controle, com livre 
acesso a ração normal com $23 \%$ de proteína, (RP) restrição protéica, com livre acesso a dieta com $8 \%$ de proteína e isoenergética; (RE) restrição energética, com acesso restrito à ração normal, cuja quantidade foi calculada de acordo com a ingestão do grupo RP (Tabela 1).

Tabela 1. Composição das dietas normo e hipoprotéica.

\begin{tabular}{|c|c|c|}
\hline & Controle* & Hipoproteíca \# \\
\hline \multicolumn{3}{|l|}{ Ingredientes (g) } \\
\hline Proteína & 230,0 & 80,0 \\
\hline Amido de milho & 676,0 & 826,6 \\
\hline Óleo de soja & 50,0 & 50,0 \\
\hline Mistura de vitaminas** & 4,0 & 4,0 \\
\hline Mistura de minerais** & 40,0 & 40,0 \\
\hline \multicolumn{3}{|l|}{ Analise } \\
\hline Energia Total (kcal) & 4070,4 & 4070,4 \\
\hline Proteina \% & 23,0 & 8,0 \\
\hline Carboidrato \% & 66,0 & 81,0 \\
\hline Lipídios \% & 11,0 & 11,0 \\
\hline \multicolumn{3}{|c|}{$\begin{array}{l}\text { *) Ração comercial (Nuvilab-NUVITAL Nutrientes LTDA, Paraná, Brasil). } \\
\text { \#) A dieta hipoprotéica foi preparada em nosso laboratório utilizando-se a ração comercial } \\
\text { acrescida com amido de milho, de forma a compensar a quantidade de proteína retirada e } \\
\text { manter o valor energético. } \\
\text { **) As misturas de sais e vitaminas foram formuladas de acordo com as recomendações do } \\
\text { American Institute of Nutrition Rodents Diets, AIN-93G, nas mesmas quantidades da dieta } \\
\text { controle (Reeveset al., 1993). }\end{array}$} \\
\hline
\end{tabular}

Nas primeiras vinte e quatro horas após o nascimento da ninhada, mantivemos o número de seis filhotes por ninhada, o que proporciona a melhor performance lactacional (Fishbeck \& Rasmussen, 1987). A restrição alimentar foi iniciada no dia do nascimento da ninhada (dia 0) e mantida até o final do período de lactação (dia 21).

Após o desmame todos os filhotes tiveram livre acesso à ração normal, com 23\% de proteína, até os 60 dias de idade. Nesta época animais de cada grupo receberam ração normal ou hipoprotéica, por 21 dias, integrando os grupos a seguir com 15 animais cada: (C/C) filhotes de mães $\mathrm{C}$, com livre acesso à ração comercial; $(\mathrm{RP} / \mathrm{C})$ filhotes de mães $\mathrm{C}$, com livre acesso à ração hipoprotéica; (C/RP) filhotes de mães RP, com livre acesso à ração comercial; $(\mathrm{RP} / \mathrm{RP})$ filhotes de mães $\mathrm{RP}$, com livre acesso à ração hipoprotéica; $(C / R E)$ filhotes de mães $R E$, com livre acesso à ração comercial; $(R P / R E)$ filhotes de mães $R E$, com livre acesso à ração hipoprotéica (Figura 1).

Diariamente e durante todo o período experimental foram avaliados a ingestão alimentar e o peso corporal dos animais. Os dados mostrados correspondem a média \pm erro padrão de 15 animais. A análise estatística foi feita utilizando-se análise de variância univariada seguida de teste de comparação múltipla de Newman-Keuls, considerando o nível de significância de $p<0,05$.

\section{RESULTADOS E DISCUSSÃO}

Após o desmame, os filhotes de mães RP consumiram menor quantidade de ração até 57 dias $(p<0,01)$, enquanto os filhotes de mães RE normalizaram a ingestão aos 37 dias de idade (Figura 2A) quando comparados ao grupo C/C. Em relação ao peso corporal, tanto os filhotes de ratas RP quanto RE apresentaram peso corporal menor que os controles até 40 dias $(p<0,01)$. Aos 55 dias observou-se uma recuperação do peso corporal da prole de ratas $R E$, enquanto as proles do grupo RP continuaram significativamente $(p<0,01)$ abaixo do peso (Figura $2 B$ ).

Estes dados mostram que filhotes de ratas lactantes submetidas à desnutrição protéica ou energética apresentam, na vida adulta, uma alteração no comportamento alimentar diferente em resposta ao tipo de desnutrição sofrida na lactação, provavelmente devido à composição do leite das mães.

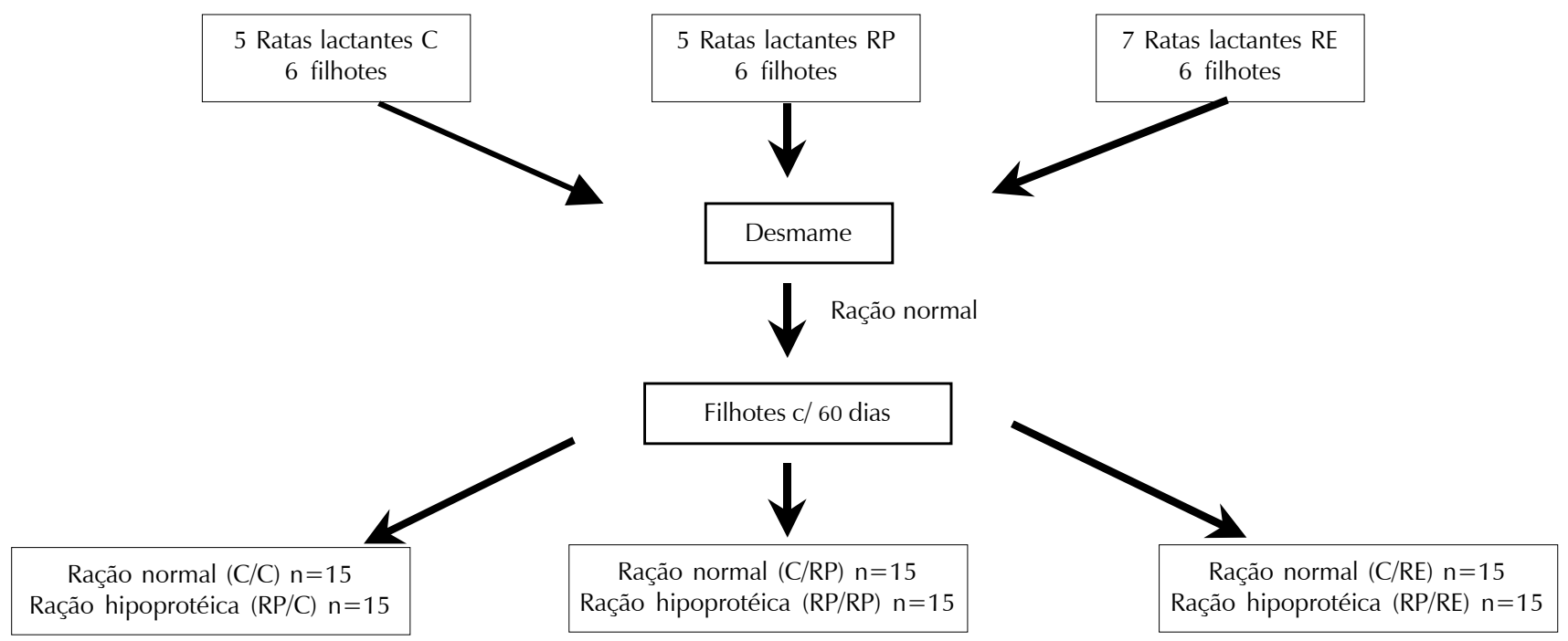

Figura 1. Protocolo. 

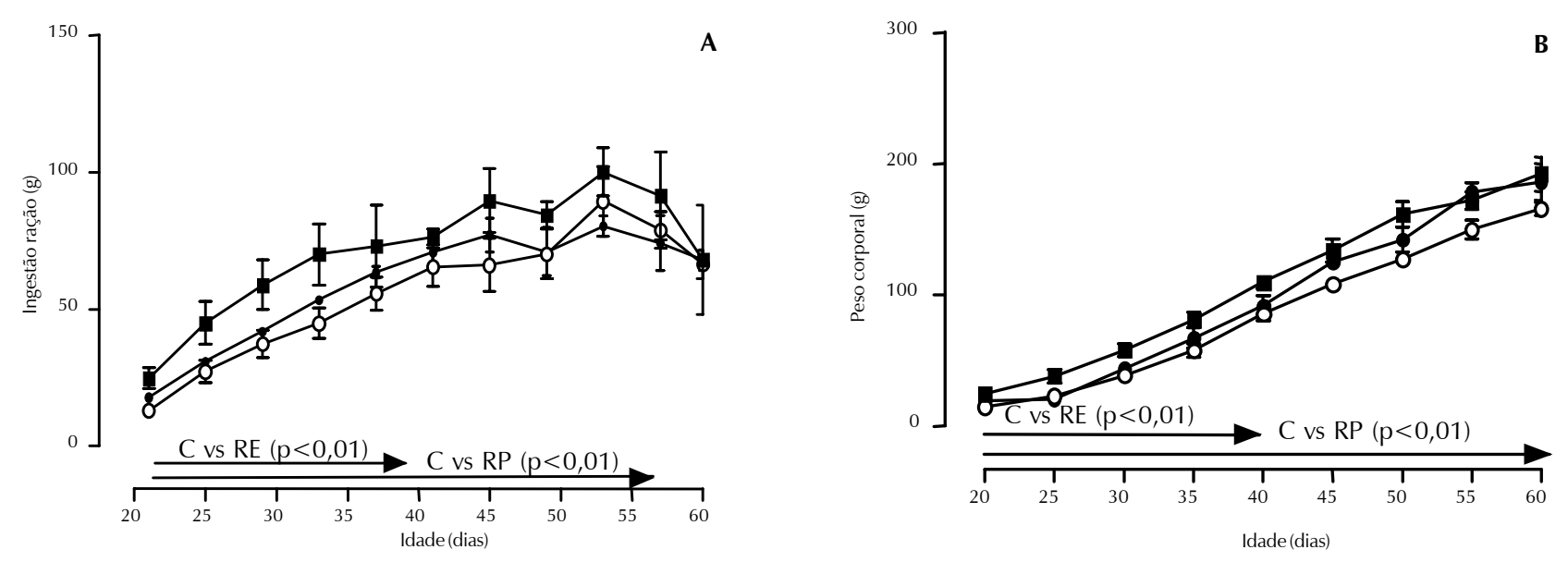

Figura 2. Consumo alimentar (A) e peso corporal (B) da prole de ratas lactantes dos grupos C ( $\mathbf{\square})$, RP (O) ou RE ( $\bullet$ ). Grupo C- 23\% de proteína; Grupo RP- 8\% de proteína; Grupo RE- 23\% de proteína com acesso limitado à quantidade de ração ingerida pelo grupo RP. Os dados são expressos como média \pm erro padrão de 15 animais por grupo.

Foi demonstrado recentemente que o leite de ratas submetidas à desnutrição protéica durante a lactação apresenta menor concentração de proteínas, enquanto o das ratas submetidas à restrição energética apresenta maior concentração de proteínas e lipídios em comparação ao das ratas com alimentação normal (Passos et al., 2000).

O resultado de peso corporal dos filhotes de ratas RP confirmam estudo anterior (Ramos et al., 1997) que demonstrou uma alteração permanente do estado nutricional dos filhotes de mães lactantes submetidas à restrição protéica. Por outro lado, os dados de peso corporal da prole de ratas RE reforçam uma hipótese recente, defendida por especialistas em nutrição humana (Rolland-Cachera et al., 1997; Rolland-Cachera, 1998), de que a quantidade de proteína ingerida na infância está positivamente correlacionada com o desenvolvimento da obesidade na vida adulta. Assim, é provável que tanto as alterações no comportamento alimentar quanto de peso corporal estejam relacionadas à composição do leite destas mães.

A Figura 3 mostra o consumo de ração de animais desnutridos na vida adulta. A restrição protéica na vida adulta (RP/C; RP/RP; RP/RE) está associada a uma menor ingestão de ração $(p<0,01)$ quando comparado aos animais $\mathrm{C} / \mathrm{C}$, independente da dieta consumida pelas mães durante o período de lactação, o que reforça estudos anteriores (Wurtman, 1983). No entanto, nossos resultados mostram que esta diminuição parece ser mais acentuada nos animais adultos em desnutrição protéica cujas mães foram submetidas à restrição protéica na lactação.

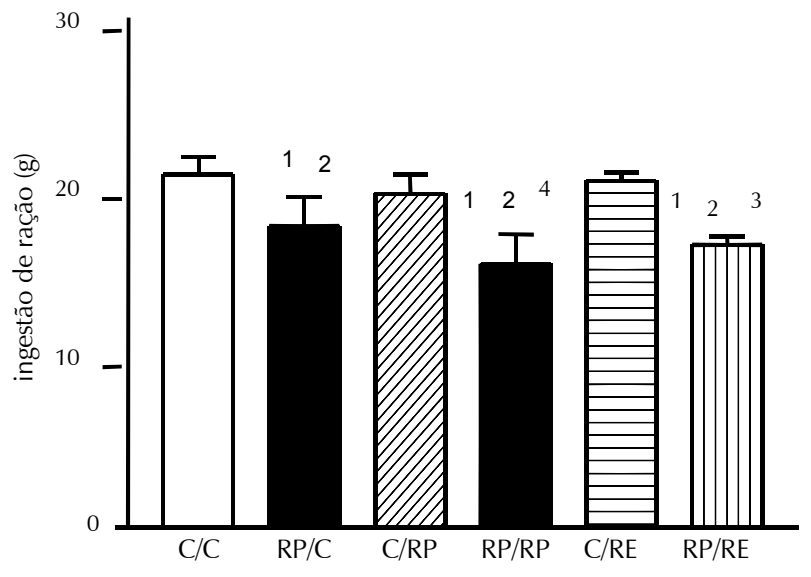

Figura 3. Consumo de ração de animais de 60 dias de idade submetidos à desnutrição protéica por 21 dias (C/C)filhotes de mães $C$, livre acesso à ração comercial; (RP/C)-filhotes de mães $C$, livre acesso à ração hipoprotéica; (C/RP)-filhotes de mães RP, livre acesso à ração comercial; $(\mathrm{RP} / \mathrm{RP})$-filhotes de mães $\mathrm{RP}$, livre acesso à ração hipoprotéica; (C/RE)-filhotes de mães RE, livre acesso à ração comercial; (RP/RE) filhotes de mães $R E$, livre acesso à ração hipoprotéica. Os dados são expressos como média \pm erro padrão de 15 animais por grupo. (1) $\mathrm{p}<0,01$ vs $\mathrm{C} / \mathrm{C}$; ${ }^{(2)} \mathrm{p}<0,01$ vs $\mathrm{C} / \mathrm{RP}$; ${ }^{(3)} \mathrm{p}<0,01$ vs $\mathrm{C} / \mathrm{RE}$; (4) $\mathrm{p}<0,05$ vs RP/C.

\section{CONCLUSÃO}

Neste estudo observamos que o estado nutricional materno durante a lactação pode determinar a ingestão e o peso corporal da sua prole aos dois meses de idade. Além disso, a resposta de um animal à restrição protéica, em relação ao comportamento alimentar, é diferente de acordo 
com a dieta consumida pelas mães durante a lactação, sendo mais intensa quando a mãe é submetida à restrição protéica. Isto sugere que a lactação pode ser o período crítico na determinação do estado nutricional futuro da prole e que a restrição protéica neste período esteja associada a uma alteração permanente no controle hipotalâmico da seleção de nutrientes da prole, reforçando o conceito de "imprinting metabólico".

\section{REFERÊNCIAS BIBLIOGRÁFICAS}

ANDERSON, G. H., LI, E.T.S., GLANVILLE, N.T. Brain mechanism and the quantitative and qualitative aspects of food intake. Brain Research Bulletin, New York, v.12, n.2, p.167-173, 1984.

BASDEVANT, A., LE BARZIC, M., GUY-GRAND, B. Comportement alimentaire: du normal au pathologique. In: GODEAU, P. Traité de Médecine Interne. Paris : Flammarion, 1995. p.1809-1824.

BAYNE, K. Revised guide for the care and use of laboratory animals avaible. Am Phys Soc Physiol, v.39, n.4, p.208-211, 1996.

FISHBECK, K.L., RASMUSSEN, K.M. Effect of repeated cycles on maternal nutritional status, lactational performance and litter growth in ad libitum-fed and chronically food-restricted rats. Journal of Nutrition, Bethesda, v.117, n.11, p.1967-1975, 1987.

MOURA, A.S., CARPINELLI, A.R., BARBOSA, F.B., GRAVENA, C., MATHIAS, P.C. Undernutrition during early lactation as an alternative model to study the onset of diabetes mellitus type II. Research Communication Molecular Pathology and Pharmacology, Westbury, v.92, n.1, p.73-84, 1996.

ONís, M., MONTEIRO, C., CluGSTON, G. The worldwide magnitude of protein-energy malnutrition: na overview from the WHO Global Database on Child Growth. Bulletin of World Health Organization, Geneve, v.71, n.6, p.703-712, 1993.

PASSOS, M.C.F., RAMOS, C.F., MOURA, E.G. Short and long term effects of malnutrition in rats during lactation on the body weight of offspring. Nutrition Research, New York, v.20, n.11, p.1605-1614, 2000.

PINE, A.P., JESSOP, N.S., OLDHAM, J.D. Maternal protein reserves and their influence on lactational performance in rats 2: Effects of dietary protein restriction during gestation and lactation on tissue protein metabolism and $\mathrm{Na}+, \mathrm{K}+$-ATPase activity. British Journal of Nutrition, v.72, n.61, p.181-197, 1994.

RAMOS, C.F., LIMA, A.P.S., TEIXEIRA, C.V., BRITO, P. D., MOURA, E.G. Thyroid function in post-weaning rats, which dams were fed a low protein diet during suckling. Brazilian Journal of Medical Biology Research, Ribeirão Preto, v.30, n.1, p.133-137, 1997.

RAMOS, C.F., TEIXEIRA, C.V., PASSOS, M.C.F., PAZOS-MOURA, C.C., LISBOA, P.C., CURTY, F.H., MOURA, E.G. Low-protein diet changes thyroid function in lactating rats. Proceedings of the Society for Experimental Biology and Medicine, Baltimore, v.224, n.4, p.256-263, 2000.

REEVES, P.G., NIELSEN, F.H., FAHEY, G.C. AIN-93 Purified diets for laboratory rodents: final report of the American Institute of Nutrition Ad Hoc Writing Committee on the reformulation of the AIN-76 rodent diet. Journal of Nutrition, Bethesda, v.123, n.11, p.1939-1951, 1993.

ROLLAND-CACHERA, M.F., DEHEEGER, M., BELLISLE, F. Nutrient balance and body composition. Reproduction, Nutrition, Development, Paris, v.37, n.6, p.727-734, 1997.

ROLLAND-CACHERA, M.F. Desequilibre nutritionnel au debut de la vie: effects a long term. Archives de Pediatrie, Paris, v.5, p.209S-211S, 1998. Supplement 2.

ROSTOM DE MELLO, M.A., OLIVEIRA FILHO, R.M., CURY, L., VALLE, L.B.S. Circulating thyroid hormone levels in young pregnant rats and their fetuses: effect of malnutrition. Annals of Nutrition and Metabolism, Basel, v.33, n.3, p.181-187, 1989.

WATERLAND, R.A., GARZA, C. Potencial mechanisms of metabolic imprinting that lead to chronic disease. American Journal of Clinical Nutrition, Bethesda, v.69, n.2, p.179-197, 1999.

WURTMAN, R.J. Behavioural effects of nutrients. Lancet, London, v.1, n.8334, p.1145-1147, 1983.

Recebido para publicação em 6 de julho e aceito em 11 de outubro de 2000. 